\title{
Photochemical Impact on Ozone Fluxes in Coastal Waters
}

\author{
L. Coleman, ${ }^{1}$ P. McVeigh, ${ }^{1}$ H. Berresheim, ${ }^{1}$ M. Martino, ${ }^{2}$ and C. D. O'Dowd ${ }^{1}$ \\ ${ }^{1}$ School of Physics and Centre for Climate and Air Pollution Studies, Ryan Institute, National University of Ireland Galway, \\ University Road, Galway, Ireland \\ ${ }^{2}$ Laboratory for Global Marine and Atmospheric Chemistry, School of Environmental Sciences, University of East Anglia, \\ Norwich NR4 7TJ, UK
}

Correspondence should be addressed to M. Martino, m.martino@uea.ac.uk

Received 27 February 2012; Accepted 12 April 2012

Academic Editor: Raymond Desjardins

Copyright (c) 2012 L. Coleman et al. This is an open access article distributed under the Creative Commons Attribution License, which permits unrestricted use, distribution, and reproduction in any medium, provided the original work is properly cited.

Ozone fluxes, derived from gradient measurements in Northeast Atlantic coastal waters, were observed to depend on both tide height and solar radiation. Peak ozone fluxes of $-0.26 \pm 0.04 \mu \mathrm{g} \mathrm{m}^{-2} \mathrm{~s}^{-1}$ occurred during low-tide conditions when exposed microalgae fields contributed to the flux footprint. Additionally, at mid-to-high tide, when water surfaces contribute predominantly to the flux footprint, fluxes of the order of $-0.12 \pm 0.03 \mu \mathrm{g} \mathrm{m}^{-2} \mathrm{~s}^{-1}$ were observed. Considering only fluxes over water covered surfaces, and using an advanced ozone deposition model that accounts for surface-water chemistry enhancing the deposition sink, it is demonstrated that a photochemical enhancement reaction with dissolved organic carbon (DOC) is required to explain the enhanced ozone deposition during daylight hours. This sink amounts to an ozone loss rate of up to $0.6 \mathrm{ppb}$ per hour under peak solar irradiance and points to a missing sink in the marine boundary layer ozone budget.

\section{Introduction}

Tropospheric ozone has negative impacts on human health and vegetation [1] and also acts as an important greenhouse gas. Recent trend analysis in background North Atlantic air at the Mace Head research station in western Ireland shows background ozone levels to be on the increase by $0.16 \mathrm{ppb}$ per annum (1988 to 2007) [2]. Mace Head is a clean marine site, representing air transported over the North Atlantic towards Europe in the marine boundary layer. Consequently, rising ozone levels at Mace Head represent rising background ozone levels. The rise in background ozone concentrations at Mace Head cannot be explained by changes in anthropogenic emission patterns, and model studies have not been able to recreate observed trends $[3,4]$; hence, there is a need to investigate processes influencing background ozone concentrations. Jenkin [5] identified gradual hemispheric ozone increase due to global-scale effects, influencing the ozone advected into Western Europe over the Atlantic as one of the three major influences on locally measured ozone data in the UK. The rise in background ozone concentration constitutes a significant contribution to regional ozone pollution, and so is of significant concern for pollution control policy makers. Hence, in order to assess the future trends in background ozone levels, the intercontinental transport of ozone should be well represented in assessment models as well as any relevant removal processes, one of which is the dry deposition of ozone to the ocean.

The deposition of ozone to surface waters via physical uptake (solubility, turbulent mixing) and chemical reactions in the surface layer [6] is an ozone removal process likely to influence surface ozone concentrations during intercontinental transport. From field measurements $[7,8]$, deposition velocity of ozone to the ocean is known to span the range of 0.53 to $1.0 \mathrm{~mm} \mathrm{~s}^{-1}$. Coleman et al. [9] describe the inclusion of the advanced ozone dry deposition parameterisation of Fairall et al. [10] in the regional climate model REMOTE. The Fairall ozone dry deposition parameterisation scheme accounts for turbulent and chemical enhancement of ozone deposition to water surfaces. Within their study, Coleman et al. [9] expanded the Fairall scheme to include ozone depletion via reactions with iodide and dissolved organic matter (DOM). The parameterisation was also adapted to account for variability of ozone diffusivity, solubility, and reactivity with sea surface temperature and to estimate emissions of volatile organoiodine (VOI) vapours following 
reactions of ozone with iodide and DOC (e.g., [11]). In the present study, the Fairall parameterisation was further developed to parameterise ozone-DOC reactions with a second-order reaction rate empirically derived from the laboratory work of [12]. Box model results of the updated Fairall parameterisation are compared to in situ ozone gradient fluxes measured at Mace Head.

\section{Measurement Methods}

Ozone gradient flux measurements were conducted on a $22 \mathrm{~m}$ tower at Mace Head atmospheric research facility [13] on the west coast of Ireland $\left(53^{\circ} 20^{\prime} \mathrm{N}, 9^{\circ} 54^{\prime} \mathrm{W}\right)$. The shoreline to the westward side of the $22 \mathrm{~m}$ tower is inhomogeneous, rocky, and slanted with a tidal region extending $50 \mathrm{~m}$ to $150 \mathrm{~m}$ from the base of the tower. Two Thermo Scientific (model 49i) photometric $\mathrm{O}_{3}$ analysers with response time of 20 seconds sampled at $22 \mathrm{~m}$ and $10 \mathrm{~m}$ heights to obtain $\mathrm{O}_{3}$ concentration profiles at 1minute intervals. Colocated with the $\mathrm{O}_{3}$ analysers, a Gill R3 3-dimensional ultrasonic anemometer sampling at $10 \mathrm{~Hz}$ was used to quantify micrometeorological parameters. The Monin-Obukhov length $(L)$ was used in conjunction with measurement height $(z)$ to calculate a dimensionless scaling parameter, $z / L$, which defined the thermal stability state of the boundary layer. This parameter was used to ensure only that data pertaining to neutral or slightly unstable conditions were considered. Simultaneous filtering for data corresponding to the Mace Head clean marine sector $\left(190^{\circ}<\right.$ wind direction $<350^{\circ}$ ) ensured the considered data corresponded to an oceanic footprint. The peak of the footprint is located approximately $1 \mathrm{~km}$ offshore, as in the study of Geever et al. [14]. The relative contributions to the flux footprints at midday on each measurement day are depicted in Figure 1.

In order to ensure data quality, intercomparisons between the $\mathrm{O}_{3}$ analysers were performed at a single height on a regular basis. The mean difference from these intercomparison periods $(0.491 \mathrm{ppb})$ was then subtracted from the difference between them to give a final gradient. Only final gradients that were larger than the mean added to standard deviation of the difference between both instruments during an intercomparison were deemed acceptable for further analysis. Such filtering of data ensured readings were not biased by instrumental drift and eliminated noise, ensuring only strong-signal gradient data were considered.

Gradient fluxes, based on $K$-theory [15] and previously deployed at Mace Head, described by Ceburnis et al. [16], were computed using the vertical profiles of ozone concentration between $10 \mathrm{~m}$ and $22 \mathrm{~m}$ and the turbulenttransfer coefficient $K$ derived from the micrometeorological measurements. This calculation assumes that the eddy diffusivity coefficients for momentum and $\mathrm{O}_{3}$ are similar, which is not always the case. Analogous to Fick's law of molecular diffusion, the $\mathrm{O}_{3}$ flux $\left(\mathrm{F}_{\mathrm{O}_{3}}\right)$ can be calculated by multiplying the vertical concentration gradient with the eddy diffusivity coefficient, $K_{m}$, as follows:

$$
\mathrm{F}_{\mathrm{O}_{3}}=-K \frac{\delta \mathrm{O}_{3}}{\delta z}
$$

From the calculated fluxes, ozone deposition velocity $\left(v_{d}\right)$ to ocean surface was calculated $\left(v_{d}=\mathrm{F}_{\mathrm{O}_{3}} / \mathrm{O}_{3}\right)$. Ideally, measured fluxes should be validated by assuring energy budget closure, but unfortunately the necessary data were not available for assessment of energy closure.

\section{Model Development}

The Fairall parameterisation, including chemical reactivity was further developed based on the laboratory studies $[12,17]$ in which the chemical enhancement of the ozone deposition velocity was quantified for iodide and DOC reactants. The reaction rate for ozone and DOC, $k_{\mathrm{DOCuM}-\mathrm{O}_{3}}$, was calculated by comparing the results from ozone-iodide reactions with the Fairall dry deposition theory and known ozone-iodide reaction kinetics [18] and determining systematic constants for the experimental setup. Results from the ozone-iodide experiments could then be extrapolated back to the ozone-DOC experiments, assuming consistent experimental setup. Fairall calculated the $\mathrm{O}_{3}$ dry deposition in terms of the sum of the surface resistance $\left(R_{w}\right)$ and aerodynamic resistance $\left(R_{a}\right)$. Jones [17] performed experiments measuring loss rates of ozone deposition to saturated iodide solutions in a similar laboratory setup. In the case of ozone deposition to a saturated iodide solution, $R_{w}$ can be assumed to be zero, and so resistance to dry deposition is due to $R_{a}$ only. Using data of Jones, $R_{a}$ was estimated as the inverse to deposition velocity and found to be $3130 \mathrm{~s} \mathrm{~m}^{-1}$. This was used as typical $R_{a}$ for laboratory conditions such as those in which these experiments were executed. Combining $R_{a}$ and the rate constant used in Magi et al. [18] for sea-surface $\mathrm{O}_{3}$ - I reactions, we can define the experimental setup in terms of Fairall's dry deposition velocity equation. A surface turbulence term $(\tau)$ is required to be combined with $R_{w}$ to replicate the Martino et al. [12] experiments. Consequently, the dry deposition velocity to seawater can be written as follows:

$$
V_{d}=\frac{1}{\left(1 / \alpha \sqrt{k_{o z-C}[C] D}\right) \tau+R_{a}}=\frac{1}{a x^{-0.5}+3130},
$$

where $\alpha$ is the solubility of ozone, $K_{o z-c}$ is the 2 nd order rate constant of ozone and reactant $C,[C]$ is the molar constant of reactant in the water surface, and $D$ is the diffusivity of ozone in seawater. First, by fitting the right hand side version of the equation to the Martino data (Figure 2), we calculate $\tau=1.47$, then we calculate the 2 nd order rate constant for ozone and DOC reactions $\left(k_{\mathrm{DOCuM}_{-} \mathrm{O}_{3}}=3.44 \mu \mathrm{M}^{-1} \mathrm{~s}^{-}\right)$. Oceanic DOC concentrations were estimated using the relationship between chlorophyll and DOC as described by Kepkay and Wells [19] based on their study in the North Atlantic: [DOC] $\mu \mathrm{M}=110+2.27[$ chlorophyll $] \mathrm{mg} / \mathrm{m}^{3}$. Typical iodide concentrations for summer-period coastal waters off the west coast of Ireland were taken as $50 \mathrm{nM} \mathrm{I} \mathrm{[20]} \mathrm{and} \mathrm{a}$ typical chlorophyll-a concentration of $1 \mathrm{mg} / \mathrm{m}^{3}$ derived from MODIS (http://oceancolor.gsfc.nasa.gov). Other variables in the model, including ozone solubility and diffusivity were set up as outlined in Coleman et al. [9]. 


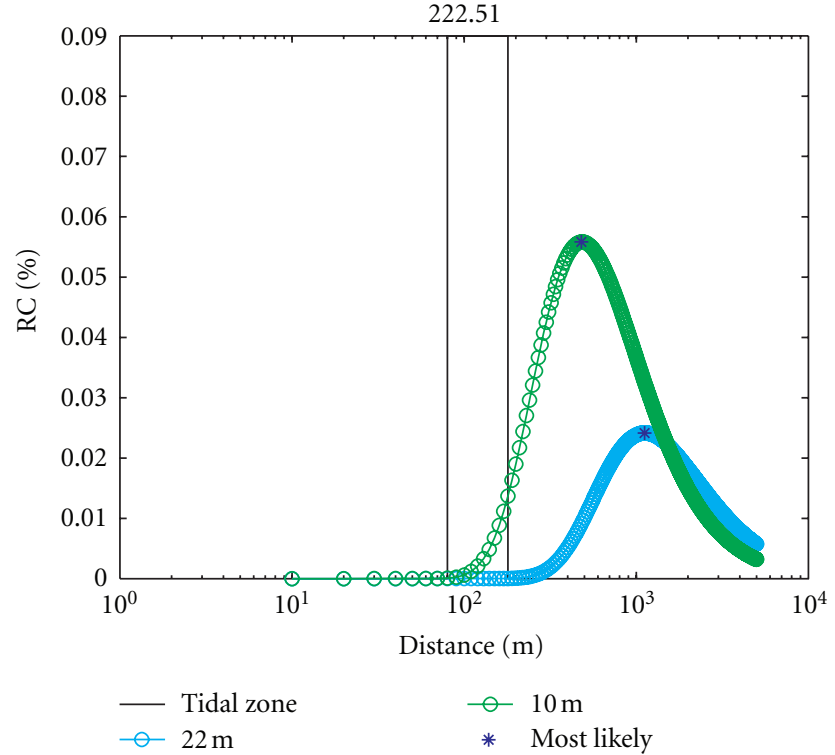

(a)

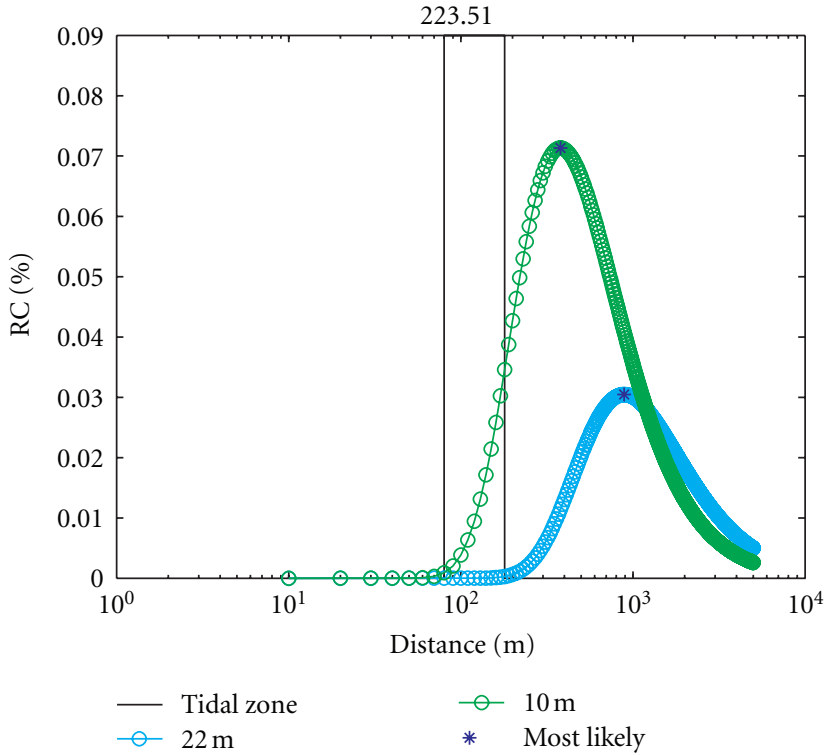

(b)

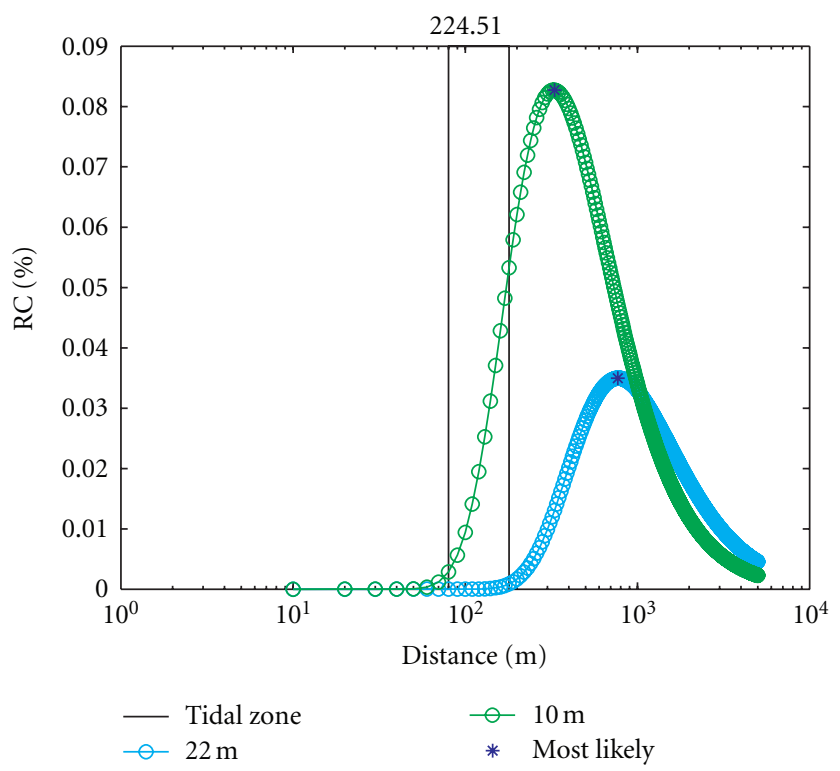

(c)

FIGURE 1: Relative contribution to flux footprint calculated at midday for relative measurement days.

\section{Results and Discussion}

The measured and modelled fluxes and corresponding deposition velocities are illustrated in Figure 3 for the duration of the short campaign study (days $222-225$ or August 10-13, 2010). The measured fluxes were averaged over 30 minute intervals. Uncertainty in measurements is represented by error bars in Figure 3. The primary source of uncertainty is in the $\mathrm{O}_{3}$ analysers which are precise only to the nearest $\mathrm{ppb}$. Periods of low tide influence the measurements, as was similarly observed by Whitehead et al. [21] and are depicted in the shaded areas. $U_{22}$ values during this period were mostly below $10 \mathrm{~m} \mathrm{~s}^{-1}$, with predominant NW wind directions. Gradient fluxes were mostly negative, indicating a surface sink. It can be noted here that low tide occurred around midday on all four days, coinciding with the daily solar radiation maximum, as shown in Figure 3.

Both the modelled and measured fluxes are in accordance with those observed by Gallagher et al. [7] using the eddy covariance technique. Although the modelled fluxes are the same order of magnitude as the measured fluxes, variations in measured fluxes are not reproduced in initial box model results. The surface transfer represents the main bottleneck in ozone deposition to water surfaces [10]. Reactivity $\left(A_{o z}\right)$, 


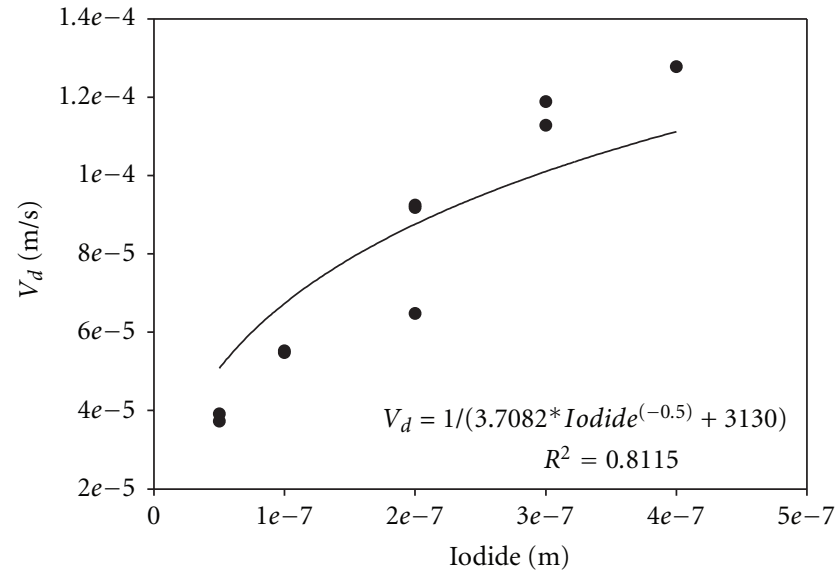

(a)

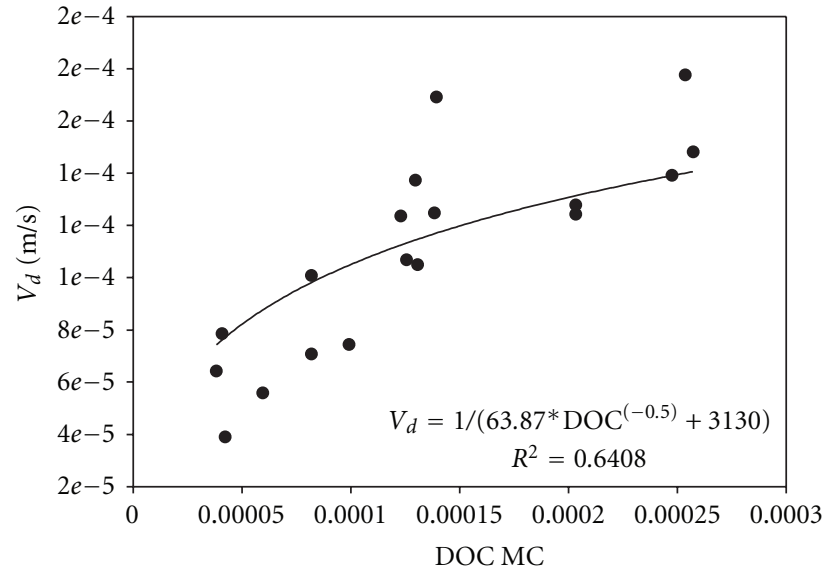

(b)

Figure 2: Experimental data from Martino et al., (2012), where deposition velocity of ozone was measured as a function of varying (a) iodide and (b) DOC concentrations.

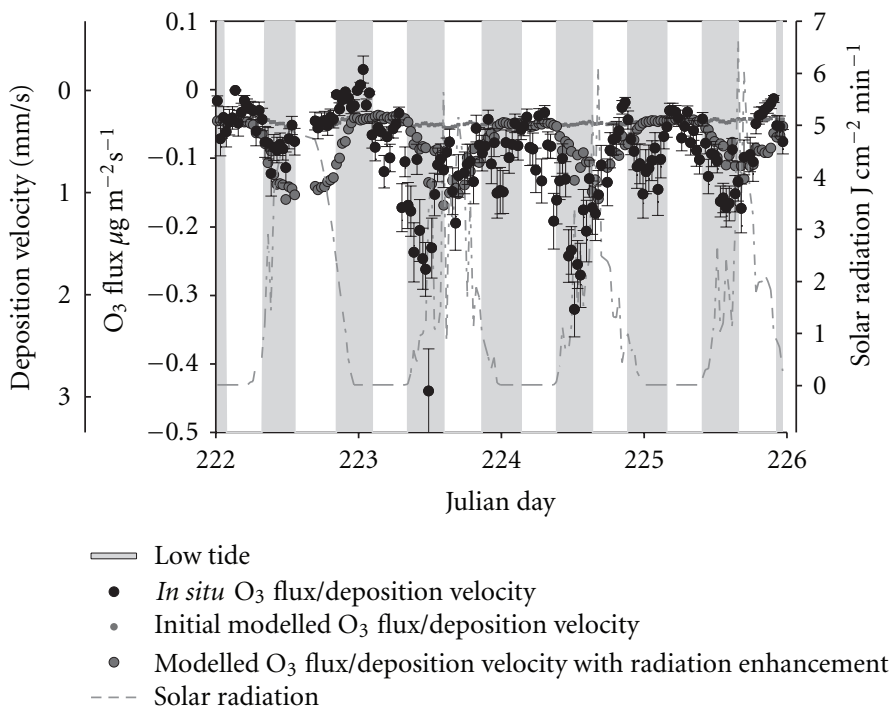

Figure 3: Ozone fluxes at Mace Head between August 10 and 13, 2010, measured using the gradient technique and modelled using deposition scheme of Fairall et al. [10].

a first order loss rate representing chemical depletion of ozone in the sea surface layer, represents the biggest uncertainty in surface transfer, and comparison with the observations suggests that some important reactivity processes are either missing or unknown.

Referring to Figure 3, it is apparent that, excluding fluxes associated with low-tide conditions, episodes of large negative fluxes coincide with high solar irradiation. This suggests that there may be photoenhancement of ozone reactions. Gas-phase reactions above the water surface but below the lowest measurement level may partially contribute to the discrepancy between the model results and measurements; however, given that halogen concentrations are more than an order of magnitude lower than $\mathrm{O}_{3}$ [22], the contribution of such reactions to the gradient is thought to be negligible; consequently, the increased flux was attributed to water-phase ozone reactions. Although Küpper et al. [23] found reactions of ozone and iodide to be lightindependent, a recent study by Reeser et al. [6] demonstrated photoenhancement of reactions between ozone and organic substances. A possible reason for the photoenhancement of ozone-organic reactions can be deduced from the study of Zepp et al. [24] which describes how UV radiation alters the availability of aquatic dissolved organic matter (DOM) to microorganisms and accelerates photodegradation of DOM which may increase ocean reactivity to ozone by exposing more reactive species. In an attempt to replicate the nontidal ozone flux trends associated with irradiance, we introduce a photochemical enhancement factor for the modelled ozoneDOC reactions, whereby ozone reactions are enhanced by a factor of 20 in the presence of maximum solar radiation, and a linear scaling was applied to the reactivity term. This 
scaling is a crude first order approximation, and the scaling limits were chosen to match the box-model results to the in situ data, results are depicted in Figure 3. While we are lacking quantitative information relating to the enhancing effect of light on ozone-DOC reactivity, it is clear that introducing this photochemical enhancement significantly improves the replication of the experimental data by the model. The inclusion of this new photochemical term results in an increase of the ozone deposition loss rate of up to $0.6 \mathrm{ppb}$ per hour compared to $0.2 \mathrm{ppb}$ per hour without the photochemistry.

Episodes of high downward ozone observed on days 223.5 and 224.5 are not reproduced by the model, but are most likely due to a combination of high wind speeds and low-tidal exposure of macroalgae. The macroalgae exposure during low tide enhances ozone deposition on both physical and chemical levels: physically, ozone deposition to the rougher macroalgae surface would be more significant than to a water surface, while chemically, exposure of macroalgae to ozone stimulates oxidative stress, inducing release of molecular iodine [25] which rapidly reacts with ambient ozone, causing further depletion and perhaps an apparent increase in the downward ozone flux. Referring to Figure 1, a significant portion of the flux footprint lies within the tidal zone, indicating an augmented tidal influence during these periods. Increased depositional fluxes observed at nocturnal high tide on days 223 and 224 are not reproduced by the model. These high fluxes occur at periods of low wind speeds, and so it is likely that the flux enhancement occurs due to variations in water phase chemical reactivity. The model parameterises oceanic chemical reactivity using typical oceanic iodide and DOC concentrations and so variations in ocean tide reactivity are not accounted for in these results.

\section{Conclusion}

Photoenhancement of ozone-DOC reactions must be considered in the ozone dry deposition parameterisation to yield results corresponding to in situ gradient flux measurements. Presuming turbulence is adequately accounted for in surface transfer in the Fairall scheme, the ozone reactivity must be solar dependent. Inclusion of the solar radiation enhancement of sea-surface ozone reactions in the ozone deposition parameterisation causes an increase in modelled ozone flux of $38.5 \%$, a significant enhancement to an ozone marine loss mechanism. Laboratory studies are required to quantify the effect of solar radiation on ozone with DOC, but this work indicates that failure to consider photoenhancement of ozone reactions with DOC would result in underestimation of ozone lost to sea surface via dry deposition, a loss mechanism especially pertinent for modelling intercontinental transport of ozone. Coupled with the knowledge that global concentrations of oceandwelling phytoplankton are in decline [26, 27], the decrease in organic matter in the Atlantic, and associated deposition flux reduction, may be a contributing factor in the previously unexplained rise in background ozone concentration as found in Mace Head [2].

\section{Acknowledgments}

The EPA, under Contracts CCRP5.3 (EASI-AQCIS), 2006AQ-MS-50 (Ozone Trends in Ireland), and CCRP-09-FS-4-2, and Air Quality-Climate Interactions are acknowledged for support of this work.

\section{References}

[1] US-EPA, "Ozone: good up high, bad nearby," edited by U.S. Environmental Protection Agency, 2003, http://www.epa.gov/ oar/oaqps/gooduphigh/.

[2] O. P. Tripathi, S. G. Jennings, C. D. O’Dowd et al., "Statistical analysis of eight surface ozone measurement series for various sites in Ireland," Journal of Geophysical Research D, vol. 115, no. 19, article D19302, 2010.

[3] O. Wild, A. M. Fiore, D. T. Shindell et al., "Modelling future changes in surface ozone:aparameterized approach," Atmospheric Chemistry and Physics Discussions, vol. 11, no. 10, pp. 27547-27590, 2011.

[4] J. E. Jonson, D. Simpson, H. Fagerli, and S. Solberg, "Can we explain the trends in European ozone levels?" Atmospheric Chemistry and Physics, vol. 6, no. 1, pp. 51-66, 2006.

[5] M. E. Jenkin, "Trends in ozone concentration distributions in the UK since 1990: local, regional and global influences," Atmospheric Environment, vol. 42, no. 21, pp. 5434-5445, 2008.

[6] D. I. Reeser, A. Jammoul, D. Clifford et al., "Photoenhanced reaction of ozone with chlorophyll at the seawater surface," Journal of Physical Chemistry C, vol. 113, no. 6, pp. 2071-2077, 2009.

[7] M. W. Gallagher, K. M. Beswick, G. B. McFiggans, H. Coe, and T. W. Choularton, "Ozone dry deposition velocities for coastal waters," Water, Air and Soil Pollution, vol. 1, pp. 233-242, 2001.

[8] D. H. Lenschow, R. Pearson, and B. B. Stankov, "Measurements of ozone vertical flux to ocean and forest," Journal of Geophysical Research, vol. 87, no. 11, pp. 8833-8837, 1982.

[9] L. Coleman, S. Varghese, O. P. Tripathi, S. G. Jennings, and C. D. O'Dowd, "Regional-scale ozone deposition to North-East Atlantic waters," Advances in Meteorology, vol. 2010, Article ID 243701, 16 pages, 2010.

[10] C. W. Fairall, D. Helmig, L. Ganzeveld, and J. Hare, "Waterside turbulence enhancement of ozone deposition to the ocean," Atmospheric Chemistry and Physics, vol. 7, no. 2, pp. 443-451, 2007.

[11] M. Martino, G. P. Mills, J. Woeltjen, and P. S. Liss, "A new source of volatile organoiodine compounds in surface seawater," Geophysical Research Letters, vol. 36, 5 pages, 2009.

[12] M. Martino, B. Lézé, A. R. Baker, and P. S. Liss, "Chemical controls on ozone deposition to water," Geophysical Research Letters, vol. 39, no. 5, article L05809, 2012.

[13] S. G. Jennings, C. Kleefeld, C. D. O’Dowd et al., "Mace head atmospheric research station-characterization of aerosol radiative parameters," Boreal Environment Research, vol. 8, no. 4, pp. 303-314, 2003.

[14] M. Geever, C. D. O’Dowd, S. van Ekeren et al., "Submicron sea spray fluxes," Geophysical Research Letters, vol. 32, 4 pages, 2005.

[15] R. B. Stull, An Introduction to Boundary Layer Meteorology, 1988.

[16] D. Ceburnis, C. D. O'Dowd, G. S. Jennings et al., "Marine aerosol chemistry gradients: elucidating primary and secondary processes and fluxes," Geophysical Research Letters, vol. 35, Article ID L07804, 5 pages, 2008. 
[17] C. Jones, Aqueous chemistry and photochemistry of volatile organic iodine in sea water, Ph.D. thesis, University of York, York, UK, 2006.

[18] L. Magi, F. Schweitzer, C. Pallares, P. Mirabel, C. George, and S. Cherif, "Investigation of the uptake rate of ozone and methyl hydroperoxide by water surfaces," Journal of Physical Chemistry A, vol. 101, no. 27, pp. 4943-4949, 1997.

[19] P. E. Kepkay and M. L. Wells, "Dissolved organic carbon in North Atlantic surface waters," Marine Ecology Progress Series, vol. 80, pp. 275-283, 1992.

[20] V. W. Truesdale, A. J. Bale, and E. M. S. Woodward, "The meridional distribution of dissolved iodine in near-surface waters of the Atlantic Ocean," Progress in Oceanography, vol. 45, no. 3-4, pp. 387-400, 2000.

[21] J. D. Whitehead, G. B. McFiggans, M. W. Gallagher, and M. J. Flynn, "Simultaneous coastal measurements of ozone deposition fluxes and iodine-mediated particle emission fluxes with subsequent CCN formation," Atmospheric Chemistry and Physics, vol. 10, pp. 255-266, 2010.

[22] A. S. Mahajan, M. Sorribas, J. C. G. Martin et al., "Concurrent observatiobs of atomic iodine, molecular iodine and ultrafine particles in a coastal environment," Atmospheric Chemistry and Physics, vol. 11, pp. 2545-2555, 2011.

[23] F. C. Küpper, L. J. Carpenter, G. B. McFiggans et al., "Iodide accumulation provides kelp with an inorganic antioxidant impacting atmospheric chemistry," Proceedings of the National Academy of Sciences of the United States of America, vol. 105, no. 19, pp. 6954-6958, 2008.

[24] R. G. Zepp, D. J. Erickson III, N. D. Paul, and B. Sulzberger, "Interactive effects of solar UV radiation and climate change on biogeochemical cycling," Photochemical and Photobiological Sciences, vol. 6, no. 3, pp. 286-300, 2007.

[25] C. J. Palmer, T. L. Anders, L. J. Carpenter, C. K. Frithjof, and G. B. McFiggans, "Iodine and halocarbon response of laminaria digitata to oxidative stress and links to atmospheric new particle production," Environmental Chemistry, vol. 2, no. 4, pp. 282-290, 2005.

[26] D. G. Boyce, M. R. Lewis, and B. Worm, "Global phytoplankton decline over the past century," Nature, vol. 466, no. 7306, pp. 591-596, 2010.

[27] W. W. Gregg, N. W. Casey, and C. R. McClain, "Recent trends in global ocean chlorophyll," Geophysical Research Letters, vol. 32, article L03606, pp. 1-5, 2005. 

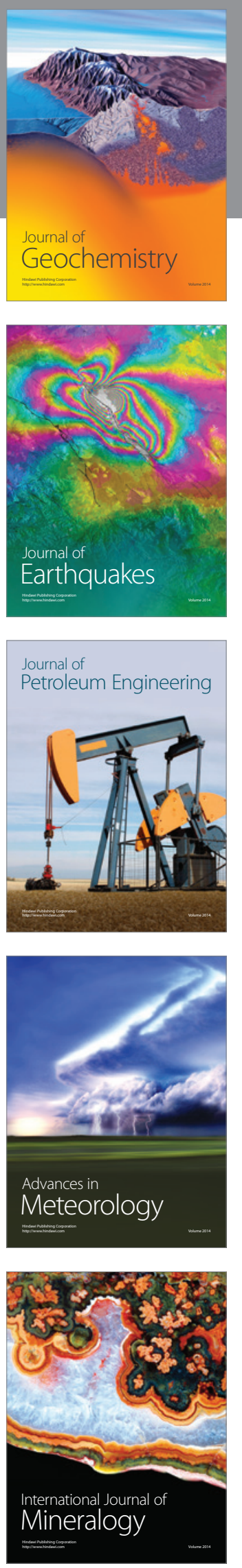
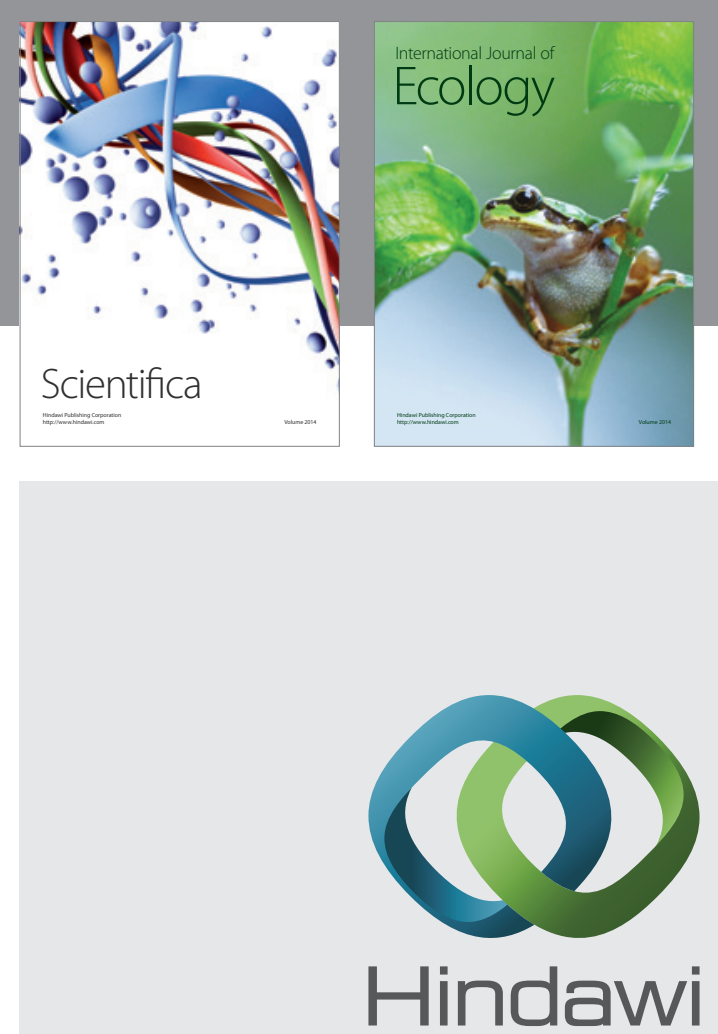

Submit your manuscripts at http://www.hindawi.com
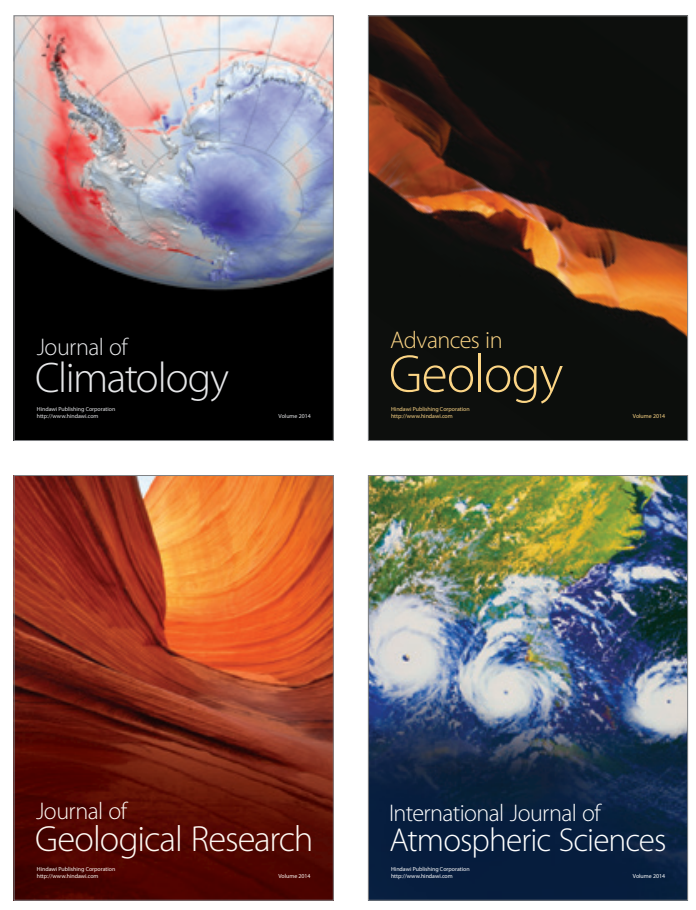
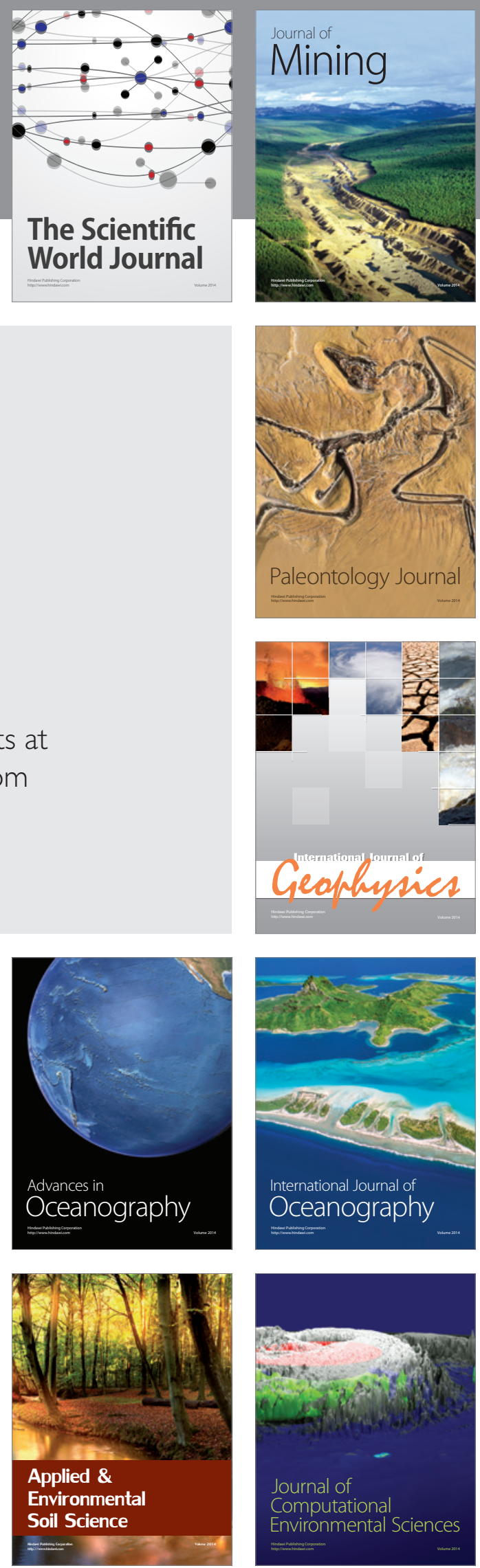